\title{
Impact of Genetic Polymorphism of Myeloid Differentiation Primary Response Gene 88, Enhancer of Zeste Homolog 2, and B-cell Lymphoma 2 like 11 in Patients with Diffuse Large B Cell Lymphoma Treated with Rituximab, Cyclophosphamide, Doxorubicin, Vincristine, and Prednisone Regimen
}

\author{
Hussam Zawam ${ }^{1}$, Noha E. Ibrahim², Rasha Salama ${ }^{1}$, Mai Samir ${ }^{3}$, Walaa Abdelfattah ${ }^{4}$, Doaa M. El Demerdash ${ }^{5}$, Dina Sabry ${ }^{3}$, \\ Sahar A. Tabak ${ }^{6}$, Rasha A. Khairy ${ }^{6 *}$ \\ ${ }^{1}$ Kasralainy Center of Clinical Oncology and Nuclear Medicine, Faculty of Medicine, Cairo University, Cairo, Egypt; ${ }^{2}$ Department \\ of Microbial Biotechnology, Genetic Engineering and Biotechnology Division, National Research Centre, Giza, Egypt; \\ ${ }^{3}$ Department of Medical Biochemistry and Molecular Biology, Faculty of Medicine, Cairo University, Cairo, Egypt; ${ }^{4}$ Department \\ of Clinical and Chemical Pathology, Faculty of Medicine, Cairo University, Cairo Egypt; ${ }^{5}$ Department of Internal Medicine, \\ Clinical Hematology Unit, Faculty of Medicine, Cairo University, Cairo, Egypt; ${ }^{6}$ Department of Pathology, Faculty of Medicine, \\ Cairo University, Cairo, Egypt
}

Edited by: Ksenija Bogoeva-Kostovska Citation: Zawam H, Ibrahim NE, Salama R, Samir M Abdelfattah W, El Demerdash DM, Sabry D, Tabak SA Khairy RA. Impact of Genetic Polymorphism of Myeloid Differentiation Primary Response Gene 88, Enhancer of with Diffuse Large B Cell Lymphoma Treated with Rituximab, Cyclophosphamide, Doxorubicin, Vincristine, and Prednisone Regimen. Open Access Maced J Med Sci. 2021 Feb 21 9(A):98-105. https://doi.org/10.3889/oamjms.2021.5697 Keywords: DLBCL; MYD88; EZH2; BCL211; Gene polymorphism; Cell of origin "Correspondence: Rasha A. Khairy, Department of athology, Faculty of Medicine, Cairo University, Cairo, gypt.E-mall: rasha_khairy80@yahoo.com Revised: 31-Jan-2021 Revised: 31-Jan-2021 Copyright: ๑ 2021 Hussam Zawam, Noha E. lbrahim Rasha Salama, Mai Samir, Walaa Abdelfattah, Doaa M. E Demerdash, Dina Sabry, Sahar A. Tabak, Rasha A. Khairy Competing Interest: The authors have declared that no competing interest exists Open Access: This is an open-access article distributed under the terms of the Creative Commons Attribution-

\begin{abstract}
BACKGROUND: Despite the growing landscape of genetic drivers in Diffuse Large B-cell Lymphoma, yet thei clinical implication is still unclear and R-CHOP regimen remains a "one size fits all" therapy. We aimed in this study to examine the prevalence of EZH2, BCL211 and MYD 88 genetic polymorphisms in DLBCL patients and correlate the results with various clinical and survival outcomes.

METHODS: Genotyping of MYD88 (rs387907272 T/C), EZH2 (rs3757441 C/T), and BCL2L11 (rs3789068 A/G) polymorphisms were conducted using real time polymerase chain reaction analysis in a total of $75 \mathrm{DLBCL}$ patients.

RESULTS: Most of our cases carried the wild TT genotype of MYD88 gene (64\%), the mutant TT genotype of EZH2 gene $(52 \%)$ and the wild AA genotype of BCL2L11 gene $(48 \%)$. Regarding cell of origin, Germinal Centre (GC) phenotype was present in $56 \%$ of cases while $44 \%$ expressed the Post-GC (PGC) phenotype. Poor response outcome to first line R-CHOP was significantly correlated with the mutated CC genotype of MYD $88(p=0.02)$, while better response to R-CHOP was significantly associated with younger age $<50$ years $(p<0.0001)$, good PS $(p=0.046)$, normal LDH level $(p=0.003)$, earlier stage $(p<0.0001)$, good IPI score $(p=0.009)$, absence of extranodal disease $(p<0.0001)$ and absence of bulky disease $(p=0.004)$. The median PFS and the 2 year OS were significantly higher in younger age, earlier stage, good IPI score, absence of extranodal disease, absence of bulky disease and in GC phenotype.

CONCLUSIONS: Our results emphasized that the mutated genotype of MYD 88 gene polymorphism is significantly associated with poor response to R-CHOP therapy.
\end{abstract}

\section{Introduction}

Diffuse large B-cell lymphoma (DLBCL) comprises a heterogeneous group of non-Hodgkin lymphoma (NHL) with different tumor biology and clinical behavior [1]. At present, chemoimmunotherapy with rituximab, cyclophosphamide, doxorubicin, vincristine, and prednisone (R-CHOP) is used as a standard treatment in all subtypes of DLBCL, despite knowing that a substantial group of patients will experience relapse or refractory disease, resulting in an overall survival (OS) rate of approximately $60 \%$ [2].

Introduction of the concept of the cell of origin (COO) using gene expression profiling (GEP) has revealed that a germinal center (GC) subtype predicts better outcome and OS than an activated B-cell-like (ABC) subtype [3]. However, GEP is not feasible in routine clinical settings; therefore, classification of $\mathrm{COO}$ based on immunohistochemical staining has been introduced in most laboratories using multiple algorithms that combine cluster of differentiation 10 (CD10), B-cell lymphoma 6 (BCL6), and multiple myeloma oncogene 1 (MUM1)/interferon regulatory factor 4 for use on routine paraffin sections [4].

The recent WHO classification of DLBCL in 2016 was based on molecular studies of biomarkers that have been introduced instead of the original subtyping based on morphology and immunohistochemistry (IHC) alone [5]. Consequently, several studies have investigated the prognostic role of different biomarkers aiming at the addition of new sub-classifications of DLBCL [6]. 
Since the introduction of next-generation sequencing, huge effort has been made to discover additional oncogenic drivers and to discriminate different subtypes of DLBCL according to specific mutational profiles [7].

The enhancer of zeste homolog 2 (EZH2) gene is located on chromosome $7 q 36$. It encodes a histone methyl transferase which catalyzes the reaction of trimethylation of histone $\mathrm{H} 3$ at Lysine 27 that results in polycomb-dependent chromatin compaction and in consequence, gene silencing [8]. Aberrant EZH2 gene activities may increase the risk of cancer development, and its overexpression is directly correlated with more advanced stages and worse clinical outcomes [9]. Moreover, single-nucleotide polymorphisms (SNPs) of EZH2 gene affect the transcriptional regulation of some genes involved in cancer progression which may influence disease susceptibility [10].

BCL 2 like 11 (BCL2L11) gene (one member of the BCL2 family) located at chromosome $2 q 13$ is a major regulator of apoptosis in T- and B-cell homeostasis. It binds to $\mathrm{Bcl}-2$-like proteins and initiates the process of apoptosis in lymphocytes which has proven to strongly affect lymphoma development [11].

Myeloid differentiation primary response gene 88 (MYD88) is an adaptor protein through which the activity of the nuclear transcription factor $\mathrm{kB}$ signaling is increased [12]. Several studies have shown that mutant MYD88 gene is associated with inferior survival in DLBCL compared to the wild type [13].

In this study, we aimed at examining the associations of EZH2, BCL211, and MYD88 risk alleles in patients with $D L B C L$ and correlated the results with the response outcome to first-line R-CHOP therapy, survival data, in addition to other clinicopathologic variables including $\mathrm{COO}$. For the best of our knowledge, this is the first study to address the clinical and survival outcomes of these three genes together in DLBCL patients.

\section{Patients and Methods}

This study included 75 patients with primary DLBCL, presented to Kasr El-Aini University Hospital, in the period from the beginning of July 2017 until the end of June 2019. The study has gained the ethical committee approval of both the clinical oncology and the pathology departments of Cairo University.

Our inclusion criteria were confirmed diagnosis of DLBCL by histopathology and IHC, sufficient tissue in retrieved paraffin blocks, full clinical data in medical records, and treatment with $\mathrm{R}-\mathrm{CHOP}$ regimen.

Exclusion criteria included scanty tissue in paraffin blocks, HIV positivity, and treatment protocols other than R-CHOP. The patients' medical records were revised and the patients' clinicopathological and survival data were documented.

Clinical staging was done according to modified Ann Arbor staging system using computed tomography and/or magnetic resonance imaging. Positron emission tomography (PET) scan was done for initial staging in some patients and for the evaluation of treatment response for all patients at the end of their treatment cycles. The parameters of the revised international prognostic index (R-IPI) were calculated for each patient.

All patients received $1^{\text {st }}$ line chemotherapy by $\mathrm{R}-\mathrm{CHOP}$ and the median number of cycles was 6 cycles (range 4-8) as intended curative therapy. The response to treatment was evaluated using the standard Lugano criteria, based on [18F] fluorodeoxyglucose (FDG) PET using the Deauville 5-point scoring system.

All data for progression-free survival (PFS) and OS had been analyzed in June 2020.

\section{Morphology and IHC}

The hematoxylin and eosin-stained slides as well as the immunostained slides were revised by two different pathologists. All studied cohort cases showed the morphologic and immunophenotyping profile of DLBCL, not otherwise specified according to 2016 WHO classification [5].

Multiple $5 \mathrm{~mm}$ thickness sections were cut from the retrieved paraffin blocks of all cases and immunohistochemical staining was conducted using the standard protocol of fully automated Ventana Medical Systems. The following antibodies were applied: CD10 (clone 56C6, Genemed, South San Francisco, CA, at 1:50 dilution), BCL6 (clone PG-B6p, DAKO, Glostrup, Denmark, at 1-25 dilution), and MUM1 (clone MUM1p, DAKO, Glostrup, Denmark, at 1:25 dilution), appropriate positive and negative controls were included in each run.

The cutoff points for evaluation of marker positivity were $\geq 30 \%$ nuclear staining for BCL6, $\geq 30 \%$, membranous staining for CD10, and for MUM1 $\geq 30 \%$ nuclear staining.

Immunostaining with CD10, BCL6, and MUM1 was directed toward the classification of cases into GC or ABC subtypes of DLBCL, according to Hans algorithm [14]; cases were classified to $G C$ and post-GC subtypes (PGC).

\section{Extraction of formalin-fixed paraffin- embedded tissue sections deoxyribonucleic acid (DNA)}

Total genomic DNA was isolated from formalinfixed paraffin-embedded tissue sections using genomic DNA extraction kits (Thermo Scientific \# K0721), as per the manufacturer's instructions. The DNA was dissolved in Tris-ethylenediaminetetraacetic acid (EDTA) buffer 
composed of $10 \mathrm{mM}$ Tris- $\mathrm{HCl}$ containing $1 \mathrm{mM}$ EDTA $\mathrm{Na} 2$ ( $\mathrm{pH}$ 7.8). Purified genomic DNA samples were quantified using ultraviolet absorbance at $260 \mathrm{~nm}$ using a Thermo Scientific NanoDrop TM and then stored at $-20^{\circ} \mathrm{C}$ until it was subjected to quantitative polymerase chain reaction (qPCR) analysis.

\section{Genotyping of the MYD88 (rs387907272 T/C), EZH2 (rs3757441 C/T), and BCL2L11 (rs3789068) A/G polymorphisms}

The SNPs on MYD88 (rs387907272 T/C), EZH2 (rs3757441 C/T), and BCL2L11 (rs3789068) A/G were identified using a real-time $\mathrm{PCR}$ protocol based on the prevalidated TaqMan MGBTM probe for allelic discrimination assay (Applied Biosystems). Briefly, $1.25 \mathrm{~mL}$ of a $40 \mathrm{X}$ combined primer and probe mix (ABI/Life Technologies, USA) was added to $12.5 \mathrm{~mL}$ of $2 X$ TaqManTM Universal PCR Master Mix (ABI/Life technologies, USA) in a $25 \mathrm{~mL}$ final volume of DNAse/RNAse-free water (Invitrogen/Life Technologies, USA) and template. The cycle conditions were $95^{\circ} \mathrm{C}$ for $10 \mathrm{~min}, 95^{\circ} \mathrm{C}$ for $15 \mathrm{~s}$, and $60^{\circ} \mathrm{C}$ for 1 min. The last two steps were repeated 40 times. The PCR run was performed on Rotor Gene real-time PCR system (Qiagen, Santa Clarita, CA). Allelic discrimination plots were produced in Statistical Package for the Social Sciences (SPSS version 16.0; SPSS, Chicago, IL).

\section{Statistical analysis}

Patients' clinicopathologic parameters were tabulated and analysis of data was done according to SPSS software version 16. Chi-square test was performed to test the correlation between different descriptive variables.

PFS was calculated from the date of diagnosis to the date of disease progression, relapse, or death from any reason. OS was calculated from the date of diagnosis until the date of last follow-up or death from any reason. The median follow-up time was analyzed from date of the end of treatment to the date of last follow-up or death from any reason.

OS and PFS were calculated using the Kaplan-Meier method and the log rank p test was used to compare the survival curves between different groups. $p<0.05$ was considered statistically significant.

\section{Results}

\section{Patients' characteristics}

The patients' clinicopathological characteristics are listed in Table 1. Most of our cases were females (48 females vs. 27 males) and most of them were younger than 50 years old $(51 / 75,68 \%)$ with a median age of 46 years.
Table 1: Characteristics of studied DLBCL cases

\begin{tabular}{|c|c|}
\hline Clinicopathologic characters & No (\%) \\
\hline \multicolumn{2}{|l|}{ Age } \\
\hline$<50$ years & $51(68)$ \\
\hline$\geq 50$ years & $24(32)$ \\
\hline \multicolumn{2}{|l|}{ Gender } \\
\hline Male & $27(36)$ \\
\hline Female & $48(64)$ \\
\hline \multicolumn{2}{|l|}{ PS } \\
\hline Good (1-2) & $63(84)$ \\
\hline Poor (3-4) & $12(16)$ \\
\hline \multicolumn{2}{|l|}{$\mathrm{HCV}$} \\
\hline No & $54(72)$ \\
\hline Yes & $21(28)$ \\
\hline \multicolumn{2}{|l|}{ HBV } \\
\hline No & $69(92)$ \\
\hline Yes & $6(8)$ \\
\hline \multicolumn{2}{|l|}{ Serum LDH level } \\
\hline Normal & $39(52)$ \\
\hline High & $36(48)$ \\
\hline \multicolumn{2}{|l|}{ IPI score } \\
\hline Good $(0)$ & $18(24)$ \\
\hline Intermediate $(1,2)$ & $18(24)$ \\
\hline Poor $(3,4,5)$ & $39(52)$ \\
\hline \multicolumn{2}{|l|}{ Stage } \\
\hline II & $12(16)$ \\
\hline III & $54(72)$ \\
\hline IV & $9(12)$ \\
\hline \multicolumn{2}{|l|}{ Extranodal disease } \\
\hline Nodal & $48(64)$ \\
\hline Extranodal & $27(36)$ \\
\hline \multicolumn{2}{|l|}{ Bulky disease } \\
\hline No & $54(72)$ \\
\hline Yes & $21(28)$ \\
\hline \multicolumn{2}{|l|}{$\mathrm{coO}$} \\
\hline GC & $42(56)$ \\
\hline PGC & $33(44)$ \\
\hline \multicolumn{2}{|l|}{ Response to R-CHOP ( $1^{\text {st }}$ line $)$} \\
\hline $\mathrm{CR}$ & $48(64)$ \\
\hline PR & $9(12)$ \\
\hline Progression & $18(24)$ \\
\hline \multicolumn{2}{|l|}{ Relapse } \\
\hline Yes & $18(24)$ \\
\hline No relapse & $57(76)$ \\
\hline \multicolumn{2}{|l|}{ MYD88 (rs387907272) T/C } \\
\hline $\mathrm{CC}$ & $6(8)$ \\
\hline TC & $21(28)$ \\
\hline $\mathrm{TT}$ & $48(64)$ \\
\hline \multicolumn{2}{|l|}{ EZH2 (rs3757441) C/T } \\
\hline $\mathrm{CC}$ & $6(8)$ \\
\hline TC & $30(40)$ \\
\hline $\mathrm{TT}$ & $39(52)$ \\
\hline \multicolumn{2}{|l|}{ BCL2L11 (rs3789068) A/G } \\
\hline AA & $36(48)$ \\
\hline AG & $33(44)$ \\
\hline GG & $6(8)$ \\
\hline
\end{tabular}

DLBCL: Diffuse large B-cell lymphoma; HCV: Hepatitis C virus; HBV: Hepatitis B virus; LDH: Lactate dehydrogenase; IPI: International prognostic index; GC: Germinal center; PGC: Post-germinal center; R-CHOP: Rituximab, cyclophosphamide, doxorubicin, vincristine, and prednisone; CR: Complete response PR: Partial response; MYD88: Myeloid differentiation primary response gene 88; EZH2: Enhancer of zeste

Staging with the modified Ann Arbor staging system showed that Stage 3 represented the main bulk of our cases (72\%), while Stages 2 and 4 represented $16 \%$ and $12 \%$, respectively. Most of our patients (84\%) had good performance status (PS) (1-2) at presentation. The high prevalence of infection with hepatitis virus in our country, especially hepatitis $\mathrm{C}$ virus (HCV), was reflected in our results where the incidence of $\mathrm{HCV}$ infection was $28 \%$.

Twenty-seven patients (36\%) had extranodal lymphoma at presentation and 36 patients (48\%) had high lactate dehydrogenase (LDH). After calculating the R-IPI score, we found that $52 \%$ of our patients (39 patients) had poor R-IPI score (>3), whereas 18 patients (24\%) had good R-IPI score 0 , and 18 patients $(24 \%)$ had intermediate R-IPI score (1-2).

All studied cohort cases displayed the morphological picture of DLBCL in hematoxylin and eosin stained sections, CD20-positive and CD3negative immunophenotyping profile (Figure $1 \mathrm{a}, \mathrm{b}$ and, 


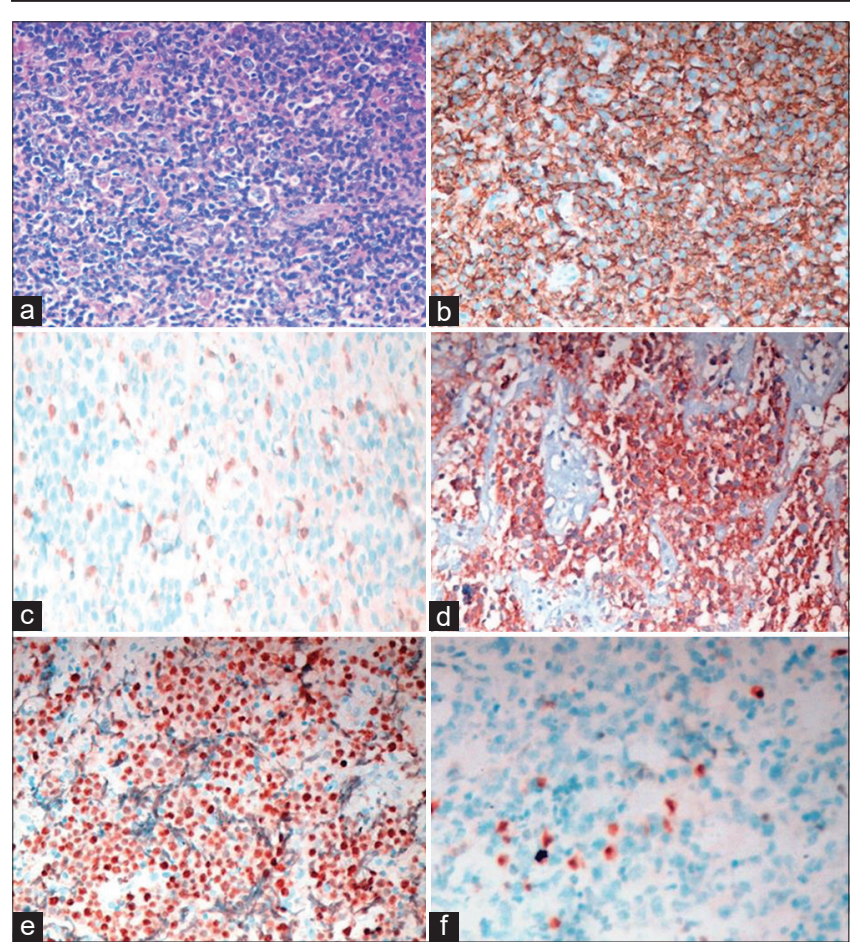

Figure 1: (a) Diffuse large B-cell lymphoma (BCL), not otherwise specified: Hematoxylin and eosin ( $\times 200$ original magnification) (b) CD20, positive membranous immunostaining in lymphoma cells (immunohistochemistry, $\times 200$ original magnification), (c) CD3: Negative immunostaining in lymphoma cells with some positive small reactive $T$ lymphocytes (immunohistochemistry, $\times 200$ original magnification), and (d) positive membranous immunostaining of CD10 in lymphoma cells (immunohistochemistry, $\times 200$ original magnification). (e) Positive nuclear immunostaining of BCL6 in lymphoma cells (immunohistochemistry, $\times 200$ original magnification), (f) Positive nuclear immunostaining of multiple myeloma oncogene 1 in lymphoma cells MUM1 (immunohistochemistry, $\times 200$ original magnification)

c respectively). Forty-two patients (56\%) had GC COO displaying CD10- and BCL6-positive immunostaining (Figure $1 \mathrm{~d}$ and e respectively) while 33 patients (44\%) had PGC COO displaying MUM1-positive immunostaining (Figure 1f), according to criteria of the applied Hans algorithm.

The core of the study was to study the genotyping of the MYD88 (rs387907272 T/C), EZH2 (rs3757441 C/T), and BCL2L11 (rs3789068) A/G polymorphisms. In the MYD-88 gene, the mutant CC genotype was present in only 6 cases $(8 \%)$, while the heterogeneous TC genotype in 21 cases $(28 \%)$ and the wild-type TT genotype in 48 cases (64\%).

Distribution of the EZH2 (rs3757441 C/T) genotypes showed that the wild CC genotype was present in 6 cases $(8 \%)$, while the TC genotype in 30 cases $(40 \%)$ and the mutant TT genotype in 39 cases $(52 \%)$.

Finally, studying the BCL2L11 (rs3789068) $A / G$ polymorphism showed that the wild-type $A A$ genotype was present in 36 cases (48\%), AG genotype in 33 cases $(44 \%)$, and the mutant GG genotype in 6 cases $(8 \%)$.
Response outcome to first-line RCHOP

After first-line treatment with R-CHOP, complete response (CR) was achieved in $64 \%$ of patients, partial response in $12 \%$ of patients, and progressive course in $24 \%$ of patients.

The better response outcome was significantly correlated with younger age $<50$ years $(p<0.0001)$, good PS $(p=0.046)$, normal LDH level $(p=0.003)$, earlier stage $(p<0.0001)$, better IPI score $(p=0.009)$, absence of extranodal disease $(p<0.0001)$, and absence of bulky disease $(p=0.004)$, as shown in Table 2 .

\section{Table 2: Correlation of patients' outcome to R-CHOP with prognostic factors including MYD88 (rs387907272 T/C), EZH2 (rs3757441 C/T), and BCL2L11 (rs3789068 A/G) polymorphisms}

\begin{tabular}{|c|c|c|c|c|c|}
\hline Patient outcome to R-CHOP & $\mathrm{CR}$ & PR & Progression & Total & p-value (Chi-square) \\
\hline \multicolumn{6}{|l|}{ Age } \\
\hline$<50$ years & 42 & 3 & 6 & 51 & \multirow[t]{2}{*}{$<0.0001$} \\
\hline$\geq 50$ years & 6 & 6 & 12 & 24 & \\
\hline \multicolumn{6}{|l|}{ PS } \\
\hline $1-2$ & 42 & 9 & 12 & 63 & \multirow[t]{2}{*}{0.046} \\
\hline $3-4$ & 6 & 0 & 6 & 12 & \\
\hline \multicolumn{6}{|l|}{ LDH } \\
\hline High & 18 & 9 & 9 & 36 & \multirow[t]{2}{*}{0.003} \\
\hline Normal & 30 & 0 & 9 & 39 & \\
\hline \multicolumn{6}{|l|}{ R-IPI } \\
\hline Good (0) & 10 & 3 & 5 & 18 & \multirow[t]{3}{*}{0.009} \\
\hline Intermediate $(1,2)$ & 18 & 0 & 0 & 18 & \\
\hline Poor $(3,4,5)$ & 20 & 6 & 13 & 39 & \\
\hline \multicolumn{6}{|l|}{ Stage } \\
\hline II & 9 & 3 & 0 & 12 & \multirow[t]{3}{*}{$<0.0001$} \\
\hline III & 38 & 3 & 13 & 54 & \\
\hline IV & 1 & 3 & 5 & 9 & \\
\hline \multicolumn{6}{|l|}{ Extranodal sites } \\
\hline No & 42 & 6 & 0 & 48 & \multirow[t]{2}{*}{$<0.0001$} \\
\hline Yes & 6 & 3 & 18 & 27 & \\
\hline \multicolumn{6}{|l|}{ Bulky disease } \\
\hline No & 37 & 9 & 8 & 54 & \multirow[t]{2}{*}{0.004} \\
\hline Yes & 11 & 0 & 10 & 21 & \\
\hline \multicolumn{6}{|l|}{$\mathrm{COO}$} \\
\hline GC & 27 & 6 & 9 & 42 & \multirow[t]{2}{*}{0.712} \\
\hline PGC & 21 & 3 & 9 & 33 & \\
\hline \multicolumn{6}{|l|}{ MYD88 (rs387907272) T/C } \\
\hline $\mathrm{CC}$ & 2 & 3 & 1 & 6 & \multirow[t]{3}{*}{0.002} \\
\hline $\mathrm{TC}$ & 9 & 3 & 9 & 21 & \\
\hline TT & 37 & 3 & 8 & 48 & \\
\hline \multicolumn{6}{|l|}{ EZH2 (rs3757441) C/T } \\
\hline $\mathrm{CC}$ & 3 & 0 & 3 & 6 & \multirow[t]{3}{*}{0.480} \\
\hline TC & 21 & 3 & 6 & 30 & \\
\hline TT & 24 & 6 & 9 & 39 & \\
\hline \multicolumn{6}{|l|}{ BCL2L11 (rs3789068) A/G } \\
\hline AA & 25 & 6 & 5 & 36 & \multirow[t]{3}{*}{0.174} \\
\hline AG & 18 & 3 & 12 & 33 & \\
\hline GG & 5 & 0 & 1 & 6 & \\
\hline
\end{tabular}

Furthermore, results revealed that the frequency of the wild-type MYD 88 (rs387907272) TT genotype was associated with better response to treatment as $77 \%$ of cases developed CR versus $33.3 \%$ and $42.8 \%$ in the mutated CC and TC genotypes, respectively, with statistically significant $p$ value $(p=0.02)$.

No significant correlation with response outcome was detected with the EZH2 (rs3757441 C/T) and BCL2L11 (rs3789068) A/G polymorphisms.

\section{Survival results}

The median follow-up period was 16.8 months (range: 11.5-28.2 months). Median PFS of the whole group was 25.7 months $(95 \% \mathrm{Cl}=19.9-31.5$ months). 
Survival results are tabulated in Table 3 . Higher PFS was significantly associated with younger age $(p<0.0001)$, earlier lymphoma stages $(p=0.015)$, better IPI score $(p=0.014)$, absence of extranodal sites $(p<0.0001)$, and absence of bulky disease $(p=0.016)$. Regarding the subgroup COO; GC showed better PFS than PGC phenotype although it did not reach statistical significance $(p=0.07)$.

Table 3: Correlation of PFS and OS with prognostic factors including MYD88 (rs387907272 T/C), EZH2 (rs3757441 C/T), and BCL2L11 (rs3789068) A/G polymorphisms

\begin{tabular}{|c|c|c|c|c|}
\hline & Median PFS (months) [95\% Cl] & $\mathrm{p}$-value & 2-year OS (\%) & $\mathrm{p}$-value \\
\hline \multicolumn{5}{|l|}{ Age } \\
\hline$<50$ & $32.5[28.4-34.5]$ & \multirow[t]{2}{*}{$<0.0001$} & 78.4 & \multirow[t]{2}{*}{0.001} \\
\hline$>50$ & $8.6[4.9-12.4]$ & & 62.5 & \\
\hline \multicolumn{5}{|l|}{ PS } \\
\hline $0-2$ & $25.7[19.9-31.6]$ & \multirow[t]{2}{*}{0.354} & 77.8 & \multirow[t]{2}{*}{0.076} \\
\hline $3-4$ & $11.6[6.7-22.7]$ & & 50.0 & \\
\hline \multicolumn{5}{|l|}{ LDH } \\
\hline High & $25.7[19.4-32.1]$ & \multirow[t]{2}{*}{0.811} & 63.9 & \multirow[t]{2}{*}{0.329} \\
\hline Normal & $\mathrm{NR}^{*}$ & & 82.1 & \\
\hline \multicolumn{5}{|l|}{ R-IPI } \\
\hline Good $(0)$ & NR & \multirow[t]{3}{*}{0.014} & 72.2 & \multirow[t]{3}{*}{0.18} \\
\hline $\begin{array}{l}\text { Intermediate } \\
(1,2)\end{array}$ & $23.3[18.3-27.7]$ & & 77.8 & \\
\hline Poor $(3,4,5)$ & $18.7[9.3-28.0]$ & & 71.8 & \\
\hline \multicolumn{5}{|l|}{ Stage } \\
\hline 2 & NR & \multirow[t]{3}{*}{0.015} & 83.3 & \multirow[t]{3}{*}{$<0.0001$} \\
\hline 3 & $32.5[26.1-38.8]$ & & 75.9 & \\
\hline 4 & $19.6[5.3-33.9]$ & & 44.4 & \\
\hline \multicolumn{5}{|c|}{ Extranodal sites } \\
\hline No & NR & \multirow[t]{2}{*}{$<0.0001$} & 89.6 & \multirow[t]{2}{*}{$<0.0001$} \\
\hline Yes & $10.5[8.3-12.8]$ & & 44.4 & \\
\hline \multicolumn{5}{|l|}{ Bulky disease } \\
\hline No & $32.5[26.1-38.8]$ & \multirow[t]{2}{*}{0.016} & 74.1 & \multirow[t]{2}{*}{0.238} \\
\hline Yes & $10.6[9.6-11.6]$ & & 71.4 & \\
\hline \multicolumn{5}{|l|}{$\mathrm{COO}$} \\
\hline GC & NR & \multirow[t]{2}{*}{0.074} & 83.3 & \multirow[t]{2}{*}{0.027} \\
\hline PGC & $25.7[19.9-31.5]$ & & 60.6 & \\
\hline \multicolumn{5}{|c|}{ MYD88 (rs387907272) T/C } \\
\hline $\mathrm{CC}$ & NR & \multirow[t]{3}{*}{0.390} & 100.0 & \multirow[t]{3}{*}{0.432} \\
\hline TC & $18.7[6.0-31.3]$ & & 61.9 & \\
\hline TT & $25.7[21.2-30.2]$ & & 75.0 & \\
\hline EZH2 (rs37574 & 1) $\mathrm{C} / \mathrm{T}$ & & & \\
\hline $\mathrm{CC}$ & $11.6[6.8-14.9]$ & 0.938 & 50.0 & 0.912 \\
\hline TC & $25.7[20.7-30.7]$ & & 76.6 & \\
\hline TT & NR & & 74.4 & \\
\hline BCL2L11 (rs37 & 9068) A/G & & & \\
\hline AA & $32.5[24.3-37.4]$ & 0.162 & 75.0 & 0.193 \\
\hline$A G$ & NR & & 66.7 & \\
\hline GG & NR & & 100.0 & \\
\hline
\end{tabular}

The median OS of the whole group was estimated to be 37.1 months $(95 \% \mathrm{Cl}=29.3$ - NR months). Due to the relatively short follow-up period, the median OS of the different subgroups could not be calculated, so we decided to calculate the 2-year OS for the analyzed subgroups. The 2-year OS of the studied group was $72 \%$.

The 2-year OS of patients younger than 50 years was $78.4 \%$ versus $62.5 \%$ in older patients ( $p=0.001$ ). Patients with Stage 2 disease have 2-year OS of $75 \%$ compared to $66.7 \%$ for Stage 3 and $44.4 \%$ for Stage $4(p<0.0001)$. The presence of extranodal disease was associated with poorer 2-year OS (22.2\% vs. $89.6 \%$ ) in those without extranodal disease. Regarding the COO, GC phenotype was associated with better outcome versus PGC origin ( $p=0.02)$.

There was no significant correlation between PFS or OS and the studied gene polymorphisms; MYD88 (rs387907272 T/C), EZH2 (rs3757441 C/T), and BCL2L11 (rs3789068).
Figures 2 and $3 \mathrm{~A}$ illustrate the PFS and Os of the studied cohort of patients respectively. Figure $3 B$ illustrates the OS of studied cohort according to cell of origin.

\section{Discussion}

DLBCL comprises a heterogeneous group of $\mathrm{NHL}$ with different molecular subtypes, encountering an abundance of altered cellular pathways. MYD88, EZH2, and BCL2L11 genetic polymorphisms and mutations have been described at various frequencies of DLBCL in some studies [7] but their clinicopathologic implications and correlations with response to therapies have not been sufficiently studied especially in Egyptian population.

Most of our cases carry the wild TT genotype of MYD88 (rs387907272) T/C gene polymorphism (64\%), the mutant TT genotype of EZH2 (rs3757441) C/T gene polymorphism (52\%), and the wild AA genotype of BCL2L11 (rs3789068) A/G gene polymorphism (48\%).

There is a wide variability in prevalence of MYD88 mutation in DLBCL patients as reported among different investigators. In addition, they have suggested that the frequency of MYD88 mutation may vary according to different tumor locations and molecular subtypes of DLBCL [13], [15]. Lee et al., in a meta-analysis of 40 studies, concluded that the overall prevalence rate of MYD88 mutation was 29\% [13].

Mutations in $\mathrm{EZH} 2$ gene were found in $22 \%$ of GC DLBCL and were absent from ABC DLBCL as reported by Morin et al. [16]. The frequency of BCL2 mutations in GC DLBCL is very high compared to ABC-DLBCL, mantle cell lymphoma, small lymphocytic lymphoma, and peripheral T-cell lymphoma as reported by Schuetz et al. [17]. Saito et al. reported also a high number of BCL2 mutations in GC DLBCL and suggested that they were the result of somatic hypermutation [18].

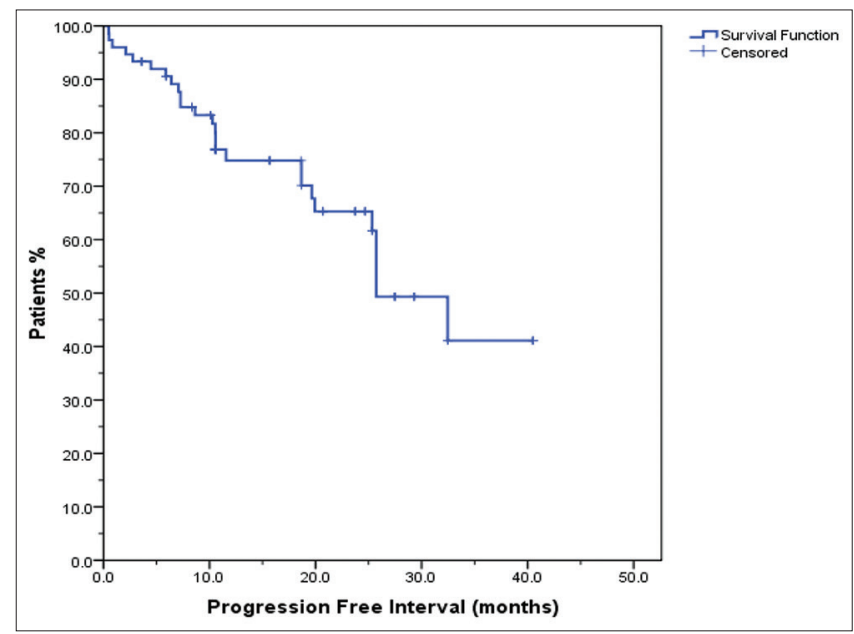

Figure 2: Progression free survival (PFS) for the whole cohort of patients 


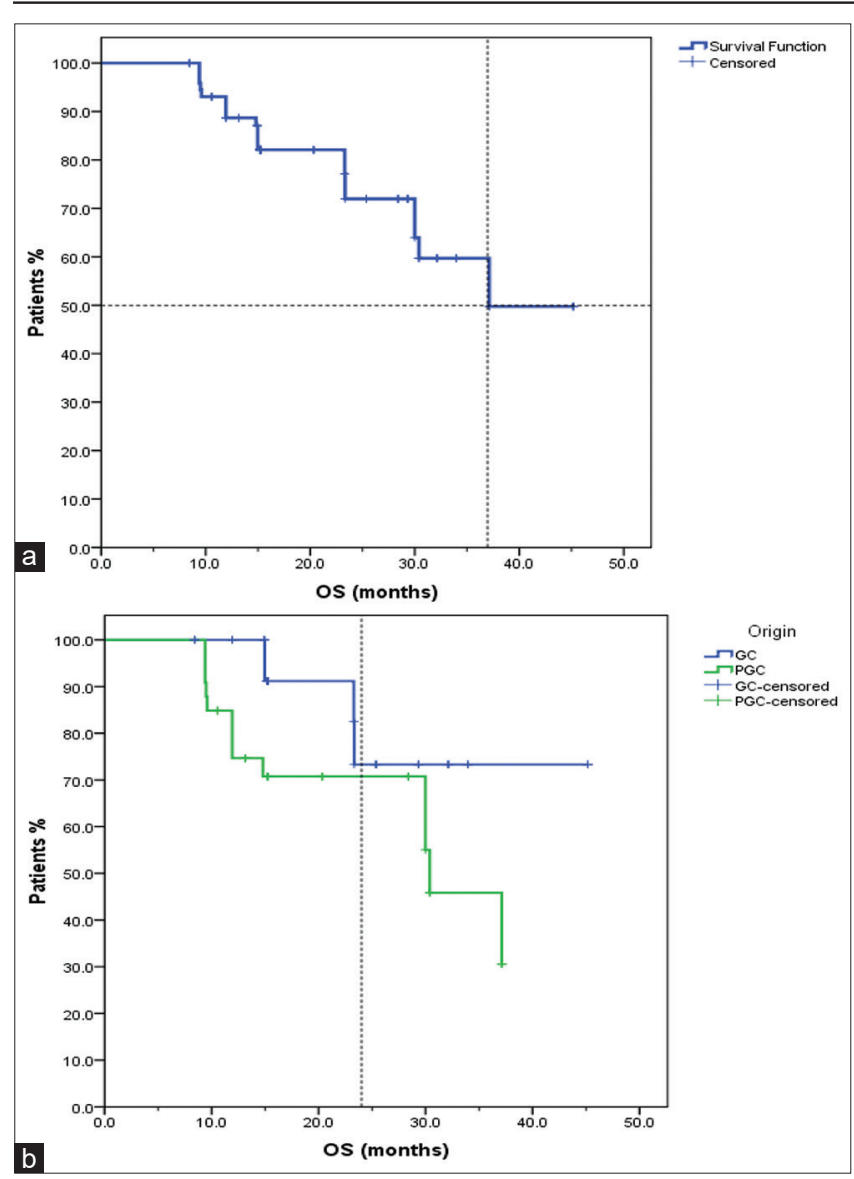

Figure 3: (3A) Overall survival (OS) of the studied cohort of patients, (3B) Kaplan -Meier analysis of OS of the studies cohort according to the cell of origin. The dashed line represents the 2-year OS cutoff

Despite the ongoing explosion of data on different molecular mechanisms in DLBCL, the fivedrug chemoimmunotherapy $\mathrm{R}-\mathrm{CHOP}$ remains the frontline standard of care for all cases. Regarding response to R-CHOP in our study, CR was achieved in $64 \%$ of patients, the median of PFS was 25.7 months, and the 2-year OS of the studied group was $72 \%$. We noticed as expected that better response outcome as well as PFS were significantly correlated with better IPI score and its individual components; younger age $<50$ years, good PS, normal LDH level, earlier stage, and absence of extranodal disease, in addition to the absence of bulky disease. Regarding the subgroup COO; GC type was associated with better OS versus PGC origin and that matches with results from other studies [2], [3], [6].

Our response outcomes coincide with the results from many studies evaluating the significant effect of IPI or adjusted IPI in predicting response to $\mathrm{R}-\mathrm{CHOP}$ as well as correlation with survivals in DLBCL [19]. The limitation of the original IPI score in predicting patients who will suffer an aggressive course of the disease highlighted the unmet need to develop and validate new prognostic tools. These tools include molecular and genetic markers to identify those patients with poorer outcome and give them more intensified therapy.
Furthermore, our results revealed that the wild MYD 88 (rs387907272) TT genotype was significantly associated with better response to R-CHOP ( $77 \%$ of cases developed CR) in comparison with other mutated CC and CT genotypes $(p=0.02)$ but this was not reflected in PFS and OS. In their series of 129 DLBCL patients, Salar et al. reported that MYD88 mutation is not only associated with worse response after $\mathrm{CHOP}$ like schedule but also with very poor response to the $2^{\text {nd }}$ line therapy and consequently to a dismal outcome [20]. On the other hand, Yu et al. studied MYD88 mutation in 53 DLBCL patients and did not find a significant association between the MYD88 mutation and treatment response or survival [21].

Hence, the prognostic value of the MYD88 mutation has been a matter of controversy, but what should be taken in consideration is that these patients when treated with the standard $\mathrm{R}-\mathrm{CHOP}$ regimen tend to have poor outcomes [13], and some series show that they may respond to the selective Bruton tyrosine kinase inhibitor "Ibrutinib" [22].

Given the crucial role of MYD88 gene and its clear clinical implications, we expect that analysis of this gene will be used more routinely in clinical practice not only as a diagnostic biomarker but also as a prognostic and therapeutic tool directing personalized medicine.

Although some studies suggested that EZH2 mutations are associated with resistance to $\mathrm{R}-\mathrm{CHOP}$ regimen [23], in our study, there was no significant correlation between response to R-CHOP therapy or survivals with either EZH2 or BCL2L11 polymorphisms. This is in contrary with findings by Deng et al. who found that $\mathrm{EZH} 2 / \mathrm{Bcl}-2$ coexpression correlated to worse objective response rate in DLBCL patients [24]. On the other hand, Cummin et al. found that overall outcomes are similar in mutant and wild-type EZH2 mutations when adjusted for COO and IPI [25].

In summary, although our study is a crosssectional study, yet it evaluated the possibility of using polymorphisms of MYD 88, EZH2, and BCL2L11 as stratifying factors with potential therapeutic implications. Our results emphasized that the mutated MYD 88 polymorphism is associated with poor response to R-CHOP therapy. This result can help us to identify a high-risk subgroup of newly diagnosed DLBCL and hence think of other therapeutic options beyond the "one size fits all" standard R-CHOP regimen.

We need to validate these results on a large scale using a multicentric pool of DLBCL patients. Furthermore, we encourage running a Phase 3 trial to randomize those patients with poor phenotypic and genotypic characteristics in the standard R-CHOP regimen versus another more intensified regimen hoping to obtain better outcomes. 


\section{Conclusion}

Our results emphasized that the mutated genotype of MYD 88 gene polymorphism is significantly associated with poor response to R-CHOP therapy, however EZH2 and BCL211 didn't reveal significant correlation with OS and PFS.

\section{References}

1. Phelan JD, Young RM, Webster DE, Roulland $S$, Wright GW, Kasbekar M, et al. A multiprotein supercomplex controlling oncogenic signalling in lymphoma. Nature. 2018;560(7718):387-91.

PMid:29925955

2. Cunningham D, Hawkes EA, Jack $A$, Qian W, Smith $P$, Mouncey $\mathrm{P}$, et al. Rituximab plus cyclophosphamide, doxorubicin, vincristine, and prednisolone in patients with newly diagnosed diffuse large B-cell non-Hodgkin lymphoma: A phase 3 comparison of dose intensification with 14-day versus 21-day cycles. Lancet. 2013;381(9880):1817-26. https://doi. org/10.1016/s0140-6736(13)60313-x

PMid:23615461

3. Alizadeh AA, Elsen MB, Davis RE, Ma CL, Lossos IS Rosenwald $\mathrm{A}$, et al. Distinct types of diffuse large B-cell lymphoma identified by gene expression profiling. Nature. 2000;403(6769):503-11.

PMid:10676951

4. Choi WW, Weisenburger DD, Greiner TC, Piris MA, Banham AH, Delabie $\mathrm{J}$, et al. A new immunostain algorithm classifies diffuse large B-cell lymphoma into molecular subtypes with high accuracy. Clin Cancer Res. 2009;15(17):5494-502. https://doi. org/10.1158/1078-0432.ccr-09-0113

PMid:19706817

5. Swerdlow SH, Campo E, Pileri SA, Harris NL, Stein H, Siebert R, et al. The 2016 revision of the World Health Organization classification of lymphoid neoplasms. Blood. 2016;127(20):237590. https://doi.org/10.1182/blood-2016-01-643569 PMid:26980727

6. Lossos IS, Czerwinski DK, Alizadeh AA, Wechser MA, Tibshirani $\mathrm{R}$, Botstein $\mathrm{D}$, et al. Prediction of survival in diffuse large-B-cell lymphoma based on the expression of six genes. N Engl J Med. 2004;350(18):1828-37. https://doi.org/10.1056/ nejmoa032520

PMid:15115829

7. Schmitz R, Wright GW, Huang DW, Johnson CA, Phelan JD, Wang JQ, et al. Genetics and Pathogenesis of Diffuse Large B-Cell Lymphoma. N Engl J Med. 2018;378(15):1396-407. PMid:29641966

8. Mozgova I, Hennig L. The polycomb group protein regulatory network. Annu Rev Plant Biol. 2015;66:269-96. https://doi. org/10.1146/annurev-arplant-043014-115627 PMid:25621513

9. Sauvageau M, Sauvageau G. Polycomb group proteins: Multi-faceted regulators of somatic stem cells and cancer. Cell Stem Cell. 2010;7(3):299-313. https://doi.org/10.1016/j. stem.2010.08.002

PMid:20804967

10. Ling Z, You Z, Hu L, Zhang L, Wang Y, Zhang M, et al. Effects of four single nucleotide polymorphisms of $\mathrm{EZH} 2$ on cancer risk: A systematic review and meta-analysis. Onco Targets Ther. 2018;11:851-65. https://doi.org/10.2147/ott.s158173 PMid:29497317

11. Hata AN, Engelman JA, Faber AC. The BCL2 Family: Key Mediators of the Apoptotic Response to Targeted Anticancer Therapeutics. Cancer Discov. 2015;5(5):475-87. https://doi. org/10.1158/2159-8290.cd-15-0011 PMid:25895919

12. Jeelall YS, Horikawa K. Oncogenic MYD88 mutation drives Tol pathway to lymphoma. Immunol Cell Biol. 2011;89(6):659-60. https://doi.org/10.1038/icb.2011.31 PMid:21519346

13. Lee JH, Jeong $\mathrm{H}$, Choi JW, Oh HE, Kim YS. Clinicopathologic significance of MYD88 L265P mutation in diffuse large B-cell lymphoma: A meta-analysis. Sci Rep. 2017;7(1):1785. https:// doi.org/10.1038/s41598-017-01998-5

PMid:28496180

14. Hans CP, Weisenburger DD, Greiner TC, Gascoyne RD, Delabie J, Ott G, et al. Confirmation of the molecular classification of diffuse large B-cell lymphoma by immunohistochemistry using a tissue microarray. Blood. 2004;103(1):275-82. https:// doi.org/10.1182/blood-2003-05-1545

PMid: 14504078

15. Ngo VN, Young RM, Schmitz R, Jhavar S, Xiao W, Lim K, et al. Oncogenically active MYD88 mutations in human lymphoma. Nature. 2011;470(7332):115-9.

PMid:21179087

16. Morin RD, Johnson NA, Severson TM, Mungall AJ, An J, Goya R, et al. Somatic mutations altering EZH2 (Tyr641) in follicular and diffuse large B-cell lymphomas of germinalcenter origin. Nat Genet. 2010;42(2):181-5. https://doi. org/10.3410/f.2738956.2402054 PMid:20081860

17. Schuetz JM, Johnson NA, Morin RD, Scott DW, Tan K, Ben-Nierah $\mathrm{S}$, et al. BCL2 mutations in diffuse large B-cell lymphoma. Leukemia. 2012;26(6):1383-90. https://doi.org/10.1038/leu.2011.378 PMid:22189900

18. Saito $M$, Novak $U$, Piovan $E$, Basso $K$, Sumazin $P$, Schneider $\mathrm{C}$, et al. BCL6 suppression of BCL2 via Miz1 and its disruption in diffuse large B cell lymphoma. Proc Natl Acad Sci U S A. 2009;106(27):11294-9. https://doi.org/10.1073/ pnas.0903854106 PMid:19549844

19. Ziepert M, Hasenclever D, Kuhnt E, Glass B, Schmitz N, Pfreundschuh $\mathrm{M}$, et al. Standard international prognostic index remains a valid predictor of outcome for patients with aggressive CD20+ B-cell lymphoma in the rituximab era. J Clin Oncol. 2010;28(14):2373-80. https://doi.org/10.1200/jco.2009.26.2493 PMid:20385988

20. Fernández-Rodríguez C, Bellosillo $B$, García-García $M$, Sánchez-González B, Gimeno E, Vela MC, et al. MYD88 (L265P) mutation is an independent prognostic factor for outcome in patients with diffuse large B-cell lymphoma. Leukemia. 2014;28(10):2104-6. https://doi.org/10.1038/leu.2014.184 PMid:24903481

21. Yu X, Li W, Deng Q, Li L, Hsi ED, Young KH, et al. MYD88 L265P mutation in lymphoid malignancies. Cancer Res. 2018;78(10):2457-62. https://doi.org/10.1158/0008-5472 can-18-0215 PMid:29703722

22. Wilson $W H$, Young RM, Schmitz R, Yang $Y$, Pittaluga $S$, Wright $\mathrm{G}$, et al. Targeting $B$ cell receptor signaling with ibrutinib in diffuse large B cell lymphoma. Nat Med. 2015;21(8):922-6. PMid:26193343 
23. Facciotto C, Casado J. Epigenetic inhibitors sensitize DLBCL cells to rituximab and doxorubicin. A $\gamma \alpha \eta$. 2019;8(5):55. https:// doi.org/10.1101/538199

24. Deng Y, Chen X, Huang C, Chen G, Chen F, Lu J, et al. EZH2/ $\mathrm{Bcl}-2$ coexpression predicts worse survival in diffuse large B-cell lymphomas and demonstrates poor efficacy to rituximab in localized lesions. J Cancer. 2019;10(9):2006-17. https://doi. org/10.7150/jca.29807

PMid:31205561

25. Cummin T, Araf S, Du MQ, Barrans S, Bentley MA, Clipson A, et al. Prognostic significance and correlation to gene expression profile of EZH2 mutations in diffuse large B-cell lymphoma (DLBL) in 2 large prospective studies. Hematol Oncol. 2017;35:158-9. https://doi.org/10.1002/hon.2438_13 